\title{
The Dangers of Lawn Chemicals at Home and Environment-A Problem Dealing Study
}

\author{
M Fazal Ur Rehman* \\ Chemistry Department, University of Education, Pakistan
}

Received: 眥 August 15, 2018; Published: 罜 August 27, 2018

*Corresponding author: M Fazal ur Rehman, Chemistry Department, University of Education, Lahore-Vehari Campus, Punjab, Pakistan

\section{Introduction}

The Lawn chemicals are the chemicals which are used in our houses as well as gardens. These chemicals are used to kill the germs, pests, harmful bacteria and viruses. In lawn chemicals, pesticides, herbicides, chemicals, and fertilizers are included. These chemicals, in most cases, are designed to kill pests, germs, bacteria and viruses by ceasing their work functions. Actually, they cease their nutrition, movement in and out of individual's body cell. When they are exposed to these micro-organisms (germs, pests, bacteria, viruses) they either directly kill them or they terminate their functions and convert them into dead organisms.

\section{Observation}

The lawn chemicals, in most cases, are designed to kill pests; however, many chemicals can also pose risks to the peoples. But, in many cases the amount of chemicals to which peoples are likely to be exposed, is too small to pose a health risk. The risks and problems caused by the lawn chemicals are observed and detailed below.

\section{Toxicity of Lawn Chemicals}

To determine risks, one must consider both the toxicity and hazard of the chemical and the likelihood of exposure. A low level of exposure to a very toxic chemical may be no more dangerous than a high level of exposure to a relatively low toxicity chemical. The health effects of chemicals depend on the type of chemical, some chemicals such as the organophosphates and carbamates; affect the nervous system, while others may irritate the skin or eyes. Some chemicals may be carcinogens, but others can affect the hormone or endocrine system in the body. The product label may have more specific instructions and try to identify and use products that are low in toxicity.

\section{Chemical Pesticides and Composts Taint Surface and Groundwater}

Yard pesticides and manures can pollute surface and groundwater. This reduces the nature of our drinking water and additionally the nature of sea-going territories and soundness of sea-going living things. Many fish and amphibian creepy crawly species are exceptionally touchy to manures and pesticides.

\section{Chemical Pesticides Threaten the Health of Children}

Children are the most vulnerable segment of our population due to their small size and their underdeveloped physiology. Children are also often the most exposed to pesticides due to their behavior (putting contaminated grass, soil and toys into mouth, breathing close to the ground). Increased exposure puts children at an unacceptably high risk from lawn pesticides.

\section{Chemical Pesticides Threaten the Health of Outdoor Pets}

Outdoor pets are highly exposed to lawn chemicals due to their behavior (licking contaminated paws and coat, breathing close to the ground, eating contaminated grass, soil and toys) and are highly vulnerable due to their small size.

\section{Chemical Pesticides Threaten the Health of Local Wildlife}

Turf-dwelling and feeding species such as the American robin, Canada goose, American widgeon, European starling, common raccoon and eastern gray squirrel are highly exposed to lawn chemicals. Granular formulations pesticides can severely impact birds that mistake the granules for seed or other food items.

\section{Chemical Pesticides and Fertilizers Reduce the Activity of Beneficial Organisms}

Healthy soil is alive with a variety of beneficial organisms that actually kill pest insects, decrease the spread of disease and help plants gather nutrients and water. For example, earthworms improve air and water circulation, decompose thatch, deposit nutrient-rich castings and help to neutralize soil (plants prefer this $\mathrm{pH}$ ). Many of these beneficial organisms are highly exposed and highly sensitive to lawn chemicals. Pesticides and fertilizers reduce their activity levels, thereby reducing a lawn's natural ability to control pests and diseases, gather nutrients and water and maintain overall health. 


\section{Local Natural Life Require Safe Spots to Live}

As an ever increasing number of rural areas infringe upon characteristic territories, natural life are compelled to escape or adjust to less perfect, frequently swarmed living spaces ready with potential perils. Introduction to garden chemicals is one such peril. Guide presentation to these pesticides and composts is perilous, just like the impacts of concoction utilize including diminished haven and nourishment openings. We can make our urban communities and towns more tenable for neighborhood untamed life by dodging grass and garden chemicals. You may considerably consider naturalizing a segment of your yard to give a more prominent assorted variety of sanctuary and sustenance sorts.

\section{Chemical Composts are a Misuse of Cash}

Concoction composts generally contain three macronutrientsphosphorus, potassium and nitrogen. They need other full scale and additionally micronutrients and incorporate no natural issue or microorganisms. Conversely, completed manure from your lawn container is a natural and regular soil alteration that gives a more entire bundle of supplements, natural issue and organisms. Completed manure is a free asset that likewise constitutes economical waste administration, broadening the life expectancy of neighborhood dumps and landfills.

\section{Chemical Pesticides Can Possibly Cause Harm all through their Lifecycles}

All phases of a pesticide's lifecycle - generation, transport, stockpiling, utilize and transfer - can possibly corrupt ecological and human wellbeing. Blasts, spills and volatilization may happen in assembling plants, storerooms, uncovering conceivably immense quantities of non-target living beings to pesticides. Transfer is a costly and disputable suggestion as individuals battle to keep stores out of their groups.

\section{Chemicals Really Debase the General Long-Haul Soundness of Your Grass and Garden}

Concoction yard mind is the wrong approach. By as often as possible applying pesticides to your yard, you may make a substance subordinate scene. As irritation species wind up noticeably impervious to the chemicals intended to kill them, more thought measurements and continuous applications are required and an endless cycle of expanding nuisance protection and pesticide utilize is built up. At the point when this happens, your grass' wellbeing is spiraling downhill [1].

\section{Basic Groups of Lawn Pesticides and their Effects} on Animal Health

\section{Organophosphates}

Organophosphate mixes incorporate probably the most dangerous chemicals utilized as a part of agribusiness. Fat- dissolvable and effortlessly transmitted all through the body, this gathering of pesticides is characterized by their hindrance of the protein cholinesterase.4 Examples of this class of chemicals are Chloryprifos and Diazinon. Harming side effects in creatures incorporate over the top salivation, "wet" respiratory sounds (in light of expanded bronchial discharges), retching, stomach torment, the runs, moderate heart rates and miosis (pinpoint students). In genuine cases, respiratory disappointment and passing can happen.

\section{Carbamates}

They cause a response like organophosphates since they restrain a similar catalyst pathway. This gathering incorporates the ordinarily utilized bug spray carbamyl. Introduction causes writhings, tipsiness, worked breathing, sickness, heaving, the runs, obviousness, muscle spasms, and extreme salivation. Toxicity of these chemicals relies upon the course of presentation.

\section{Phenoxy and Benzoic Corrosive Herbicides}

Like 2,4 D, MCPP, and MCPA influence the focal sensory system. Harming indications incorporate automatic jerking, loss of sensation, retching, stomach torments, looseness of the bowels, shortcoming, exhaustion, dermatitis, and hurting muscles. Canines and felines that don't discharge acids as effectively are particularly touchy to this compound. An EPA-financed think about found that 2,4-D is effectively followed inside, uncovering kids and pets at levels ten times higher than pre-application levels. Another examination demonstrated that presentation to phenoxy-treated yards and greenhouses appeared to drastically expand the danger of bladder tumor in Scottish Terriers.

\section{Pyrethroids}

These are recorded as conceivable cancer-causing agents by the US EPA and influence the focal and fringe sensory systems. Ordinarily utilized chemicals like Permethrin and Resmethrin are in this gathering. Harming side effects incorporate muscle tremors, hyperexcitability, melancholy, ataxia, heaving, seizures, anorexia, and passing. Presentation to Resmethrin caused expanded thyroid and liver weight in grown-up mutts, and introduction to these chemicals is connected to hurt in neurological improvement.

\section{Organochlorines}

These are a substance class that incorporates surely understood harmful and steady mixes, for example, PCBs, PCE, and DDT. Intense pesticide harming side effects incorporate muscle tremors and jerks, respiratory issues, and seizures. Demise is caused by respiratory disappointment amid maintained seizures as well as high body temperature. Long haul presentation is connected to neurological harm, respiratory disease, and different sorts of growths. The organochlorine Lindane is currently limited in the US, and is utilized basically as a seedcoating operator and is a dynamic fixing in sedated shampoos to slaughter lice and scabies. 
Nonetheless, different organochlorines are still broadly being used. Endosulfan is exceedingly poisonous to the sensory system, and represents a noteworthy hazard to felines and mutts on account of its intense harmfulness.

\section{Formation of Questions}

The questions arose from these observations are:

a) Why these chemicals are used as they infect the health in several ways?

b) Why these chemicals contaminate the ground and surface water?

c) How these chemicals disrupt the aquatic lives?

d) How these chemicals reduce the working activity of beneficial organism?

e) Why we use these chemical as also knowing that of wastage of money?

\section{Sample Collection}

As we collect a sample of the lawn chemicals including the sprays, pesticides, herbicides and fertilizers. These are applied to the home plants as well as gardens. While the flowers, plants and trees are taken under the examination.

\section{Analytical Technique}

To detect the effect of these chemicals, the techniques used are mixing of fertilizers within the solvent generally water, spraying the pesticides by special methods and also herbicides are used.

\section{Sample Preparation}

To test the effects of lawn chemicals, a sample of some flowers, plants and trees are prepared. These plants are also sensitive to use of these chemicals.

\section{Experimentation}

The variety of these chemicals were applied to the selected sample of plants and trees. They were applied in different amounts.
Some pesticides are mixed with water and other solvents and plants are provided with. Some trees are provided with some other fertilizers to increase their growth. Some chemicals (Liquefied) are also sprayed on them to kill other microorganisms.

\section{Data Collection}

After application of these toxic chemicals on plants, trees and flowers, the incoming results are collected. The results were the color of plants, their growth, their fruit production rate and also quantity. While the other results were the diseases caused by the use of these chemicals spreading in the environment, in children and also in fruits.

\section{Results and Discussion}

From the collected data, following results are appeared. These chemicals contaminate the surface and ground water. They make it unfit for drinking. They spread the diseases in humans like throat diseases, reproductive problems. They disturb the endocrine system. They also disturb the aquatic life in underground water pools. They also disturb the activity of naturally created pests, bacteria etc. They give the rapid growth and development in plant. Also give the more quantity of fruits. But these fruits also have some diseases.

\section{Conclusion}

These results show that the lawn chemicals are not safe to use. These are no eco-friendly to the environment and also living organisms. These chemicals can be stopped to use and their alternatives are to be used to overcome these issues appearing in environment.

\section{References}

1. Randy De Vaul (2006) The Dangers of Lawn Chemicals at Home. Environmental Chemistry.
(C) This work is licensed under Creative

To Submit Your Article Click Here: Submit Article

DOI: $10.32474 /$ AOICS.2018.03.000168

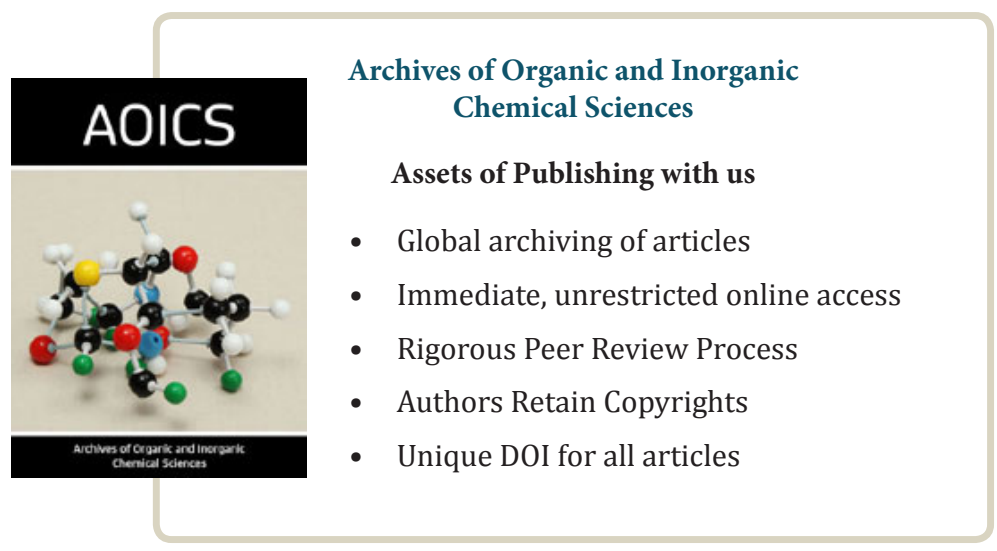

